\title{
Income Inequality Affects the Psychological Health of Only the People Facing Scarcity
}

Psychological Science 2018, Vol. 29(12) 1911-1921 (C) The Author(s) 2018 Article reuse guidelines: sagepub.com/journals-permissions DOI: $10.1177 / 0956797618798620$ www.psychologicalscience.org/PS @SAGE

at

\author{
Nicolas Sommet, Davide Morselli, and Dario Spini
}

Swiss National Centre of Competence in Research LIVES, University of Lausanne

\begin{abstract}
Following the status-anxiety hypothesis, the psychological consequences of income inequality should be particularly severe for economically vulnerable individuals. Oddly, however, income inequality is often found to affect vulnerable low-income and advantaged high-income groups equally. We argue that economic vulnerability is better captured by a financial-scarcity measure and hypothesize that income inequality primarily impairs the psychological health of people facing scarcity. First, repeated cross-sectional international data (from the World Values Survey: 146,034 participants; 105 country waves) revealed that the within-country effect of national income inequality on feelings of unhappiness was limited to individuals facing scarcity ( $\approx 25 \%$ of the World Values Survey population). Second, longitudinal national data (Swiss Household Panel: 14,790 participants; 15,595 municipality years) revealed that the within-life-course effect of local income inequality on psychological health problems was also limited to these individuals (<10\% of the Swiss population). Income inequality by itself may not be a problem for psychological health but, rather, may be a catalyst for the consequences of financial scarcity.
\end{abstract}

\section{Keywords}

income inequality, financial scarcity, happiness, psychological health, open data, open materials

Received 2/26/18; Revision accepted 6/28/18

Over the past half century, the inflation-adjusted incomes of top earners have grown faster than the incomes of middle or bottom earners, leading to unprecedented levels of income inequality (e.g., in the United States; Piketty \& Saez, 2014). Social scientists have begun to extensively investigate the psychological consequences of such a rise in income inequality (for a recent review, see Buttrick \& Oishi, 2017). In particular, they have focused on the possibility that income inequality is positively linked to feelings of unhappiness and psychological health problems.

In The Spirit Level, Wilkinson and Pickett (2010) further discussed this possibility. They argued that greater income inequality increases the salience of economic stratification, making individuals more aware of their and others' status and heightening status anxiety. From the authors' perspective, such income-inequality-based status-evaluation anxieties should manifest in a feeling of "blueness," downheartedness, or even clinical depression. The hypothesis has been rightfully labeled the status-anxiety bypothesis (Layte, 2011) and has achieved popular, scientific, and political success: The Spirit Level has sold tens-if not hundreds-of thousands of copies, has been cited more than 9,000 times, and has even been discussed in the English parliament.

However, empirical evidence is not always congruent with the status-anxiety hypothesis. The deleterious influence of income inequality on psychological health is far from being consistent across studies. For instance, the association between income inequality and feelings of unhappiness has sometimes been reported as positive (Diener, Diener, \& Diener, 1995; Oishi, Kesebir, \& Diener, 2011; Oshio \& Urakawa, 2014) but perhaps just as often has been reported as negative or null (Kelley \& Evans, 2017; Rözer \& Kraaykamp, 2013; Zagorski, Evans, Kelley, \& Piotrowska, 2014; for a meta-analysis, see Ngamaba, Panagioti, \& Armitage, 2017; for a review,

\section{Corresponding Author:}

Nicolas Sommet, University of Lausanne, Bâtiment Géopolis, Bureau \#5785, Quartier UNIL-Mouline, CH-1015 Lausanne, Switzerland E-mail: nicolas.sommet@unil.ch 
see Schneider, 2016). Regarding the association between income inequality and mental disorder, a recent metaanalysis revealed that this association was positive on the whole (Ribeiro et al., 2017). However, the pooled effect size was very small (Cohen's $d=0.06$ ), and heterogeneity between the studies was very high (explaining up to $90 \%$ of the variation in findings). This kind of heterogeneity led some scholars to argue that the psychological effects of income inequality could be Type I errors (Snowdon, 2010).

However, heterogeneity might also indicate the presence of moderators. Following from the status-anxiety hypothesis, the most obvious potential moderator is status: Because income inequality is purported to generate status-related anxiety, it would be only logical that income inequality prompts anxiety primarily among low-status individuals (e.g., those at the bottom of the pay scale; for similar reasoning, see Van Deurzen, Van Ingen, \& Van Oorschot, 2015). Again, the results are largely inconsistent across studies. A few studies have shown that local inequality relates to stronger feelings of unhappiness, psychological distress, or depression incidence among low-income respondents compared with high-income respondents (Ahern \& Galea, 2006; Lin, Zhang, Chen, \& Ling, 2017; Oishi et al., 2011). However, the apparent majority of studies showed that individual income does not moderate the relation between income inequality and subjective well-being (Kelley \& Evans, 2017), economic worries (Roth, Hahn, \& Spinath, 2017), positional concerns (Burns, Tomita, \& Lund, 2017), status anxiety (Layte \& Whelan, 2014), depressive symptoms (Van Deurzen et al., 2015), or the prevalence of dysthymic, depressive, and anxiety disorders (Sturm \& Gresenz, 2002).

For many scholars, the body of literature indicates that income inequality exerts a comparable contextual influence across income groups (e.g., Subramanian \& Kawachi, 2006). Wilkinson and Pickett (2010) argued that the effects of income inequality are "not confined just to the least well-off" (p. 181), affecting "the majority of the population [and] not just a poor minority" (Pickett \& Wilkinson, 2017, p. 2). The underlying idea is that someone is always above oneself on the economic ladder and that even wealthy individuals may suffer from invidious upward social comparisons with the super rich (for a related discussion, see Präg, Mills, \& Wittek, 2013; see also Cheung \& Lucas, 2016). However, this assumption contradicts well-established findings: Individuals at the bottom of the hierarchy are known to feel more anxious about social threats in their environment, whereas individuals at the top are more sensitive to social rewards (for a review, see Keltner, Gruenfeld, \& Anderson, 2003). Moreover, it is at odds with the model of challenge and threat: Income inequality should worry only individuals who perceive themselves as having insufficient resources to cope with financial stressors, not those who perceive themselves as having sufficient resources (for a review, see Blascovich, 2013).

A reason why income inequality has not been (systematically) found to be more harmful to the most economically vulnerable individuals may be that most of the extant research uses individual income as a moderating variable. Income may have limited diagnostic value for economic vulnerability because objective indicators of socioeconomic position often have less predictive utility than more comprehensive assessments (Singh-Manoux, Adler, \& Marmot, 2003). Mullainathan and Shafir (2014) recently developed an alternate conceptualization of economic status, namely, financial scarcity. They defined financial scarcity as a mind-set stemming from situations in which people have "too little income to cover . . day-to-day expenses" (p. 4). In the case of income, economic vulnerability implies having low resources according to the researchers' criteria (e.g., below a certain threshold; Lin et al., 2017), whereas in the case of financial scarcity, economic vulnerability implies having insufficient resources according to the respondents' perspective (e.g., unsustainable household indebtedness).

Mani, Mullainathan, Shafir, and Zhao (2013) studied the effect of financial scarcity among Indian sugarcane farmers. These farmers experience cycles of poverty: Before harvest, they are crushed by loans (financial scarcity), whereas after harvest, they are suddenly flush with cash (financial abundance). The authors found that financial scarcity generates a chronic financial pressure that impedes cognitive functioning. Similar quasiexperimental designs show that financial scarcity leads to increases in cortisol levels, higher consumption of anxiolytics, and poorer mental health (for a review, see Haushofer \& Fehr, 2014). It is legitimate to think that income inequality is particularly unbearable for people facing financial scarcity. In areas of higher (vs. lower) income inequality, wealthier others may act as a constant reminder of the intractable economic situation of people facing scarcity, further reducing the latter's ability to cope with financial stress and impairing their psychological health. However, we see no reason for income inequality to affect individuals experiencing financial abundance (or even financial equilibrium, i.e., having just enough resources to meet expenditures), at least with respect to psychological health.

\section{Methodological Precautions, Overview, and Hypotheses}

We aimed to combine economic and survey data to test whether the effects of income inequality depend on 
financial scarcity. When studying the psychological consequences of income inequality, most scholars compare national societies (or large subunits of these societies, such as U.S. states). This type of cross-cluster comparison has been the target of three main methodological criticisms. First, the number of clusters is often very small; for instance, Wilkinson and Pickett (2010) sometimes compared only a dozen countries. When statistical power is that low, the observed contextual effects may simply be driven by noise, which is likely to lead to false conclusions (Snowdon, 2010). Second, there are countless possible confounding variables (e.g., cultural background, historical legacy, welfare facilities; see Hiilamo \& Kangas, 2014). Third, research on income inequality tends to weave a causal narrative, although the internal validity is critically low (Goldthorpe, 2010). A parsimonious solution that addresses these three issues involves the use of temporal data (ideally, longitudinal) with cluster-mean-centered indicators of income inequality (Enders \& Tofighi, 2007). Such a multilevel technique enables researchers to avoid misleading between-cluster comparisons by estimating the pooled within-country or within-region effects of income inequality over time.

We implemented this analytical strategy when analyzing two sets of secondary temporal data. First, we used the largest existing repeated cross-sectional data set, the World Values Survey (WVS; 105 country waves nested in 40 countries), and tested the following hypothesis: Income inequality is a predictor of feelings of unhappiness only for individuals facing financial scarcity. Second, we used a large national longitudinal data set, the Swiss Household Panel (SHP; 15,595 municipality years nested in 1,745 municipalities), with the aim of complementing the WVS data while using (a) more local income-inequality indicators (because income inequality seems psychologically more meaningful at a smaller geographic scale; see Johnston \& Newman, 2016, pp. 175-177), (b) a more narrowly focused measure of psychological health problems (an SHP variable also used by the Swiss Health Observatory to determine the national prevalence of mental disorders, which is more specific than a general measure of feelings of unhappiness), and (c) longitudinal data. We tested the following hypothesis: Income inequality is a predictor of psychological health problems only for individuals facing financial scarcity. Complete materials, raw economic data, Stata .do files, and instructions to retrieve the WVS and SHP data and reproduce our findings are available through Figshare (https://figshare.com/s/0bfe1946433 7b17fb326).

\section{WVS Data}

First, we aimed to test whether the worldwide withincountry effect of income inequality on feelings of unhappiness is stronger when individuals are experiencing financial scarcity than when experiencing equilibrium or abundance.

\section{Metbod}

Participants and procedure. We pooled the responses from the WVS, which is an internationally representative repeated cross-sectional survey. We considered the last four waves of assessment (1994-1998, 1999-2004, 20052009, 2010-2014) because financial scarcity was not assessed prior to this period. Moreover, we considered only the countries for which both the WVS responses and the income-inequality estimates were available for at least two waves (because we focused on the withincountry effects of income inequality; for the list of these countries, as well as the number of participants per country and country wave, see Table S1 in the Supplemental Material available online).

The sample comprised 146,034 participants $(76,570$ women, 69,364 men, 100 unspecified; age: $M=41.81$ years, $S D=16.36$ ); $53.80 \%$ of the participants worked full time or part time, $15.30 \%$ had a college degree, and the mean self-reported estimation of income was $4.52(S D=$ 2.29) on an 11-point scale (1, lowest, to 11, highest). Participants were embedded in 105 country waves and 40 countries ( 2.63 waves per country). The average number of inhabitants per country wave was 79.19 million $(S D=$ 187.80 ), the poverty head-count ratio at $\$ 1.90$ (i.e., the percentage of the population living on less than 1.90 constant international dollars a day) was $0.11(S D=0.15)$, the unemployment rate was $0.09(S D=0.06)$, and the gross domestic product (GDP) per capita was 12.37 thousand constant international dollars $(S D=14.75){ }^{1}$

Variables. For correlation matrices for the lower- and higher-level variables, see Table S2 in the Supplemental Material.

Feelings of unhappiness. We used the WVS variable feelings of unhappiness. Participants reported their level of unhappiness using a scale ranging from 1, very happy, to 4 , not at all happy $(M=1.92, S D=0.76)$.

National income inequality. The World Bank annual national estimates of the Gini coefficient were used as a measure of income inequality. For each country, we averaged the annual estimates corresponding to the four waves of the WVS and obtained 105 country-wave estimations. The Gini coefficient describes the household income distribution for a given country during a given wave and can range from 0 (perfect equality: All households from the country wave have an equal share of income) to 1 (perfect inequality: One household from the country wave has all the income and the other households have none; $M=.40, S D=.10$ ). 
Financial scarcity. The WVS variable family savings during past year was used as a measure of financial scarcity. For the previous year, participants indicated whether their family (a) "saved money" (financial abundance-resources are more than sufficient to cover expenses; $22.75 \%$ of the participants), (b) "just got by" (financial equilibrium-resources are just sufficient to cover expenses; 50.31\% of the participants), (c) "spent some savings and borrowed money," or (d) "spent savings and borrowed money" (the latter two corresponding to financial scarcity-resources are not sufficient to cover expenses; $26.94 \%$ of the participants; for the number of participants per group and wave, see Table S3 in the Supplemental Material). ${ }^{2}$ Financial scarcity and selfreported estimation of income were moderately correlated (Kendall's tau-b was $r=-.26, p<.001$ ).

\section{Results}

We used multilevel linear regression modeling. We treated the responses of the 146,034 participants (Level 1) as nested in 105 country waves (Level 2), themselves nested in 40 countries (Level 3; for a graphic representation of the data structure, see Fig. S1 in the Supplemental Material). Maximum likelihood was used as the method of estimation.

Focal predictors. The feelings-of-unhappiness variable was regressed on the following focal predictors: the Gini coefficient, financial scarcity, and their hypothesized interaction. Regarding the Gini coefficient, we used clustermean centering (Enders \& Tofighi, 2007). We subtracted the country-specific mean of the Gini coefficient from the score for each country wave. Using cluster-mean centering, one can obtain an unambiguous and unbiased estimate of the pooled within-cluster effects: A negative value indicates a lower level of income inequality at the time of measurement than the country average, whereas a positive value indicates a higher level of income inequality.

Regarding financial scarcity, we used contrast coding (Rosenthal \& Rosnow, 1985). A planned contrast aimed to compare participants experiencing financial scarcity with participants in a situation of financial equilibrium or abundance (respective weights were $2 / 3,-1 / 3,-1 / 3$ ), whereas the orthogonal contrast aimed to ensure that there was no difference between financial equilibrium and abundance (respective weights were $0,+0.5,-0.5$ ). We expected a cross-level interaction between the cluster-mean-centered Gini coefficient and the planned contrast. In other words, we expected the within-country effects of income inequality to be stronger for the participants experiencing financial scarcity than for the other participants.
Control variables. We decided a priori to control for four Level 2 potential confounding variables regularly discussed in the literature (e.g., Wilkinson \& Pickett, 2006): size of area (total population), poverty head-count ratio, unemployment rate, and GDP. As for the Gini coefficient, we used cluster-mean centering. However, we decided-also a priori-to control for five Level 1 sociodemographic variables: participant's sex, age, education level, employment status, and income. Continuous variables were grand-mean centered.

Multiple imputation by chained equations (MICE) was used to generate 10 imputed data sets and account for missing values of the 10 control variables, which ranged from $0.001 \%$ (sex) to $17.86 \%$ (poverty rate). The conclusions were the same with or without MICE and with or without the 10 control variables (for the full set of results, see Table S4 in the Supplemental Material). Finally, we also controlled for the mere effect of time (wave number), as well as for the between-country random variation of the effect of the Gini coefficient.

Main analysis. Table 1 presents the full set of results. Consistent with the hypothesis, results showed that the interaction between the Gini coefficient and the planned contrast was significant, $b=1.19,95 \%$ confidence interval $(\mathrm{CI})=[0.77,1.62], p<.001$ (see Fig. 1). Specifically, the within-country effect of the Gini coefficient on feelings of unhappiness was positive for individuals experiencing financial scarcity, $b=1.71,95 \% \mathrm{CI}=[0.43,2.99], p=.009$, whereas it was not significantly different from zero for individuals experiencing financial equilibrium, $b=0.66$, $95 \% \mathrm{CI}=[-0.60,1.92], p=.303$, or abundance, $b=0.37$, $95 \% \mathrm{CI}=[-0.94,1.68], p=.581$. The interaction between the Gini coefficient and the orthogonal contrast was not significant, $b=0.29,95 \% \mathrm{CI}=[-0.22,0.81], p=.260$, suggesting that the within-country effect of the Gini coefficient did not differ between individuals in situations of financial equilibrium and abundance.

\section{Supplemental analysis.}

Predictive utility of financial scarcity versus income. One of our theoretical arguments is that income is a poorer diagnostic of economic vulnerability than scarcity. Thus, as a second step, we included the interaction between the Gini coefficient and (standardized) income in our main model. ${ }^{3}$ The interaction was in the opposite direction from that predicted, $b=0.41,95 \% \mathrm{CI}=[0.20,0.61]$, $p<.001$. Specifically, the within-country effect of the Gini coefficient on feelings of unhappiness was more positive for high-income individuals ( $+1 S D), b=1.06,95 \% \mathrm{CI}=$ $[-0.32,2.43], p=.132$, than for low-income individuals $(-1 S D), b=0.24,95 \% \mathrm{CI}=[-1.14,1.62], p=.736$. A joint postestimation test of coefficients suggested that the Gini Coefficient $\times$ Scarcity interaction had a higher predictive 
Table 1. Results From the Multilevel Models Testing the Interactive Effects of Income Inequality (Cluster-Mean-Centered Gini Coefficient) and Financial Scarcity on Feelings of Unhappiness and Psychological Health Problems

\begin{tabular}{|c|c|c|c|c|}
\hline \multirow[b]{2}{*}{ Variable } & \multicolumn{2}{|c|}{$\begin{array}{l}\text { WVS data: feelings of } \\
\text { unhappiness } \\
(n=146,034)\end{array}$} & \multicolumn{2}{|c|}{$\begin{array}{l}\text { SHP data: psychological } \\
\text { health problems } \\
(n=88,892)\end{array}$} \\
\hline & $b$ & $95 \% \mathrm{CI}$ & $b$ & $95 \% \mathrm{CI}$ \\
\hline Intercept & $1.95^{* * * *}$ & {$[1.87,2.02]$} & $2.39^{* * * * *}$ & {$[2.34,2.44]$} \\
\hline Gini coefficient & 0.91 & {$[-0.34,2.16]$} & $0.88^{*}$ & {$[0.08,1.71]$} \\
\hline Planned contrast: scarcity vs. equilibrium and abundance & $0.12^{* * * *}$ & {$[0.11,0.13]$} & $0.20^{* * * * *}$ & {$[0.16,0.25]$} \\
\hline Orthogonal contrast: equilibrium vs. abundance & $0.11^{* * * *}$ & {$[0.10,0.12]$} & $0.11^{* * * *}$ & {$[0.09,0.14]$} \\
\hline Gini Coefficient $\times$ Planned Contrast & $1.19 * * * *$ & {$[0.77,1.62]$} & $2.89^{* *}$ & {$[1.10,4.64]$} \\
\hline Gini Coefficient $\times$ Orthogonal Contrast & 0.29 & {$[-0.22,0.81]$} & 0.16 & {$[-0.89,1.19]$} \\
\hline Sex $(0=$ women, $1=$ men $)$ & $0.02^{* * * * *}$ & {$[0.01,0.02]$} & $-0.60^{* * * * *}$ & {$[-0.65,-0.54]$} \\
\hline Age (standardized) & $0.05^{* * * *}$ & {$[0.05,0.06]$} & 0.00 & {$[-0.03,0.02]$} \\
\hline Education level $(0=$ no degree, $1=$ college degree $)$ & $-0.01 *$ & {$[-0.02,0]^{\mathrm{a}}$} & -0.02 & {$[-0.09,0.04]$} \\
\hline Employment status $(0=$ not working, $1=$ working $)$ & $-0.01^{\text {** }}$ & {$[-0.02,0]^{\mathrm{a}}$} & $-0.11^{* * * *}$ & {$[-0.14,-0.08]$} \\
\hline Income (standardized) & $-0.11^{* * * *}$ & {$[-0.11,-0.10]$} & $-0.03^{* * * * *}$ & {$[-0.04,-0.02]$} \\
\hline Total population (standardized) & 0.36 & {$[-0.47,1.20]$} & $0.07^{* * *}$ & {$[0.02,0.11]$} \\
\hline Poverty head-count ratio/rate & -0.20 & {$[-0.75,0.36]$} & $0.56^{\dagger}$ & {$[-0.13,1.13]$} \\
\hline Unemployment rate/ratio & $1.35^{*}$ & {$[0.09,2.61]$} & -0.09 & {$[-0.20,0.03]$} \\
\hline GDP/income per capita (standardized) & $0.20^{\dagger}$ & {$[-0.04,0.44]$} & 0.00 & {$[-0.03,0.04]$} \\
\hline Wave/year (centered on the midpoint) & $-0.07^{* * * *}$ & {$[-0.11,-0.04]$} & $0.03^{* * * * *}$ & {$[0.02,0.03]$} \\
\hline Country/municipality random intercept & 0.24 & {$[0.19,0.30]$} & 0.05 & {$[0.03,0.07]$} \\
\hline Country/municipality random slope-Gini coefficient & 1.33 & {$[0.21,8.35]$} & 8.76 & {$[2.74,21.30]$} \\
\hline Country wave/municipality year random intercept & 0.10 & {$[0.08,0.12]$} & 0.01 & {$[0,0.01]$} \\
\hline Household random intercept & & & 0.32 & {$[0.26,0.37]$} \\
\hline Participant random intercept & & & 1.85 & {$[1.78,1.92]$} \\
\hline Level 1 residual & 0.69 & {$[0.69,0.70]$} & 1.95 & {$[1.93,1.97]$} \\
\hline
\end{tabular}

Note: For the World Values Survey (WVS) data, CIs are confidence intervals, whereas for the Swiss Household Panel (SHP) data, CIs are credibility intervals. Income, poverty, and gross domestic product (GDP)/income per capita were standardized for ease of reading and result

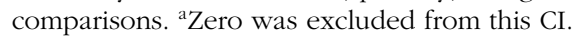

${ }^{\dagger} p<.10 . * p<.05 .{ }^{* * *} p<.01 . * * * p<.001$.

utility than the Gini Coefficient $\times$ Income interaction, $\chi^{2}(1, N=133,950)=23.46, p<.001$.

Robustness check against measurement error. The fact that our outcome variable was a single-item measure could be a source of measurement error. Following the same approach as Kelley and Evans (2017), we sought to combine the WVS feelings-of-unhappiness and dissatisfactionwith-your-life variables into a single unhappiness score. The two items were well correlated $(r=.50, p<.001)$. We rescaled them in equal intervals from 0 to 10 and computed the mean (0, lowest unhappiness, to 10, highest unhappiness; $M=3.38, S D=2.28$ ). We built the same multilevel model as before, using this composite unhappiness score as the outcome variable. The interaction between the Gini coefficient and the planned contrast remained significant, $b=3.85,95 \% \mathrm{CI}=[2.65,5.04], p<$ .001 (for the simple slopes and the full set of results, see the Supplemental Material, including Table S5).

\section{SHP Data}

Second, we aimed to replicate the WVS findings using (a) more local economic indicators, (b) a more narrowly focused measure of psychological health problems, and (c) longitudinal data.

\section{Metbod}

Participants and procedure. We pooled the responses from the SHP, which is a national representative prospective longitudinal survey. We considered the first 15 years of assessment (1999-2013) because the annual municipal estimates of income inequality after this period had not yet been released. Moreover, we considered only the municipality years for which these estimates were available.

The sample comprised 14,790 participants $(7,914$ women, 6,876 men; age: $M=45.98$ years, $S D=18.23$ ); across the years, $68.01 \%$ of the participants worked, 


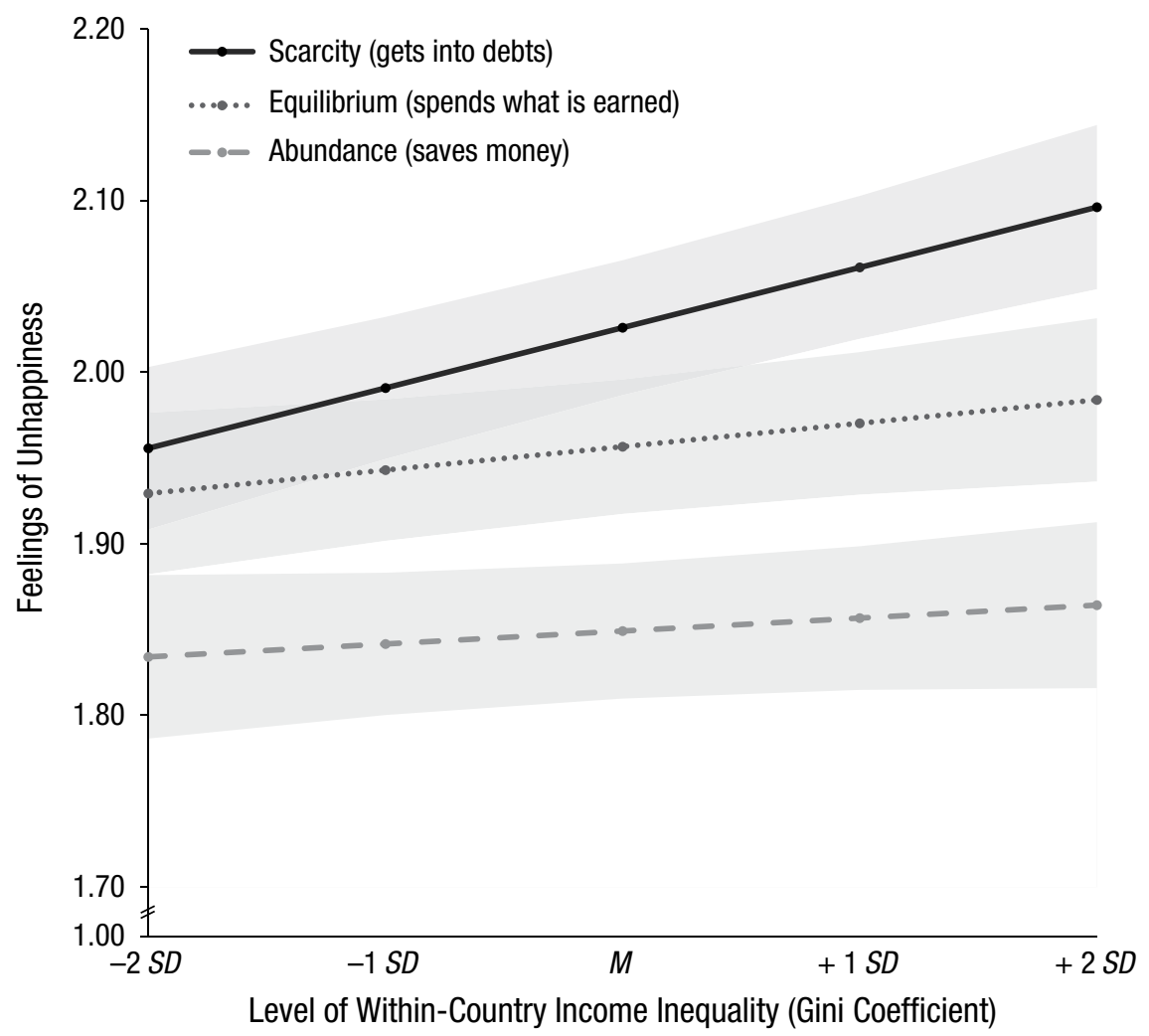

Fig. 1. World Values Survey data: within-country effects of income inequality on feelings of unhappiness for individuals in a situation of financial scarcity, equilibrium, or abundance. Shaded areas represent standard deviation from the mean; for the sake of readability, the $y$-axis is scaled from 1.70 to 2.20 (although the possible values of feelings of unhappiness range from 1.00 to 4.00 ).

$13.92 \%$ had a college degree, and their mean annual household net income was 101,967 CHF ( $S D=93,070$; $1 \mathrm{CHF} \approx$ US $\$ 1$ ). Participants' responses were embedded in 7,978 households, 15,595 municipality years, and 1,745 municipalities ( 8.47 years per municipality). The average population per municipality year was 5.57 thousand $(S D=15.83)$; the best available poverty-rate estimate, namely, the percentage of households with a taxable income lower than 20,000 CHF, was 0.13 ( $S D=$ 0.06); the employment-to-population ratio (the municipal unemployment rate was not available) was $0.42(S D=$ $0.26) ;{ }^{4}$ and the per capita net income was 38.82 thousand $\mathrm{CHF}(S D=13.08)$.

Variables. For correlation matrices for the lower-level and higher-level variable, see Table S2.

Psychological health problems. The SHP variable depression, blues, anxiety: frequency served as a measure of psychological health problems. Participants reported the frequency with which they "have negative feelings such as having the blues, being desperate, suffering from anxiety or depression" using a scale ranging from 0 , never, to 10 , always $(M=2.04, S D=2.06)$.
Municipal income inequality. The Swiss Federal Statistical Office annual municipal Gini coefficient was used as a measure of income inequality (15,595 municipalityyear estimations). The Gini coefficient describes the household income distribution for a given municipality during a given year $(M=.42, S D=.07)$.

Financial scarcity. The SHP variable income: assessment of income and expenses served as a measure of financial scarcity. As with the WVS data, participants indicated whether their household (a) "can save money" (financial abundance; 53.57\%), (b) "spends what it earns" (financial equilibrium; 37.37\%), (c) "eats into its assets," or (d) "gets into debt" (the latter two corresponding to financial scarcity; $9.06 \%$; for the number of households per group and year, see Table S3). Again, financial scarcity and annual household income were only moderately correlated $(r=-.29, p<.001)$.

The SHP data included extra variables that were close to the construct of financial scarcity. Consistently, individuals experiencing financial scarcity were found to be more likely to have arrears of payments, pay monthly premiums linked to a debt, earn less than the minimum income to make ends meet, and encounter 
difficulty in managing household income compared with individuals experiencing financial equilibrium or abundance (see Table S6 in the Supplemental Material). These results provide evidence of the convergent validity of the measure.

\section{Results}

As with the WVS data, we used multilevel modeling. However, the data structure was more complex. The data set included 88,892 lower-level responses (Level 1) nested in 14,790 participants (Level 2a). Additionally, the responses were cross-classified by 7,978 households (Level 2b) and by 15,595 municipality years (Level 2c), which were themselves nested in 1,745 municipalities (Level 3). The units are said to be cross-classified because lower-level responses in a given cluster were not subclassified by the further factor (for a graphic representation, see Fig. S2 in the Supplemental Material). This classification means that participants can leave their household or move from one municipality to another over time (such movement concerned 24.98\% of the participants). Given the complexity of the data structure, Markov chain Monte Carlo was used as the estimation method (because it uses a Bayesian framework, CIs are now credibility intervals, but we report frequentist two-tailed $p$ values; Dunn, Richmond, Milliren, \& Subramanian, 2015).

Focal predictors. The variable psychological health problems was regressed on the following focal predictors: the Gini coefficient, financial scarcity, and their hypothesized interaction. Regarding the Gini coefficient, we again used cluster-mean centering. This time, we subtracted the participant-specific mean of the Gini coefficient from the score for each response (because participants can move from one municipality to another over time). Thus, a negative value indicated relative equality within the participant's life course, whereas a positive value indicated relative inequality. Regarding financial scarcity, we used contrast coding with the same weights as in the WVS data, and we expected the same interaction between the Gini coefficient and the planned contrast.

Control variables. We decided a priori to control for the same four contextual potential confounding variables as with the WVS data (cluster-mean-centered population, poverty, unemployment, and per capita income in the municipality year), for the same five sociodemographic variables, as well as for the mere effect of time and the between-municipality random variation of the effect of the Gini coefficient. Because MICE was too computationally demanding, we relied on a single imputation procedure to account for missing values on the 10 control variables, which ranged from less than $0.01 \%$ (age) to $8.20 \%$ (poverty rate). The conclusions of the main analysis were the same with or without imputation and with or without the 10 control variables (for the full set of results, see Table S2).

Main analysis. Table 1 presents the full set of results. Consistent with the hypothesis, results showed that the interaction between the Gini coefficient and the planned contrast was again significant, $b=2.89,95 \% \mathrm{CI}=[1.10$, 4.64], $p=.001$ (see Fig. 2). Specifically, the within-lifecourse effect of the Gini coefficient on psychological health problems was positive for the individuals experiencing financial scarcity, $b=2.82,95 \% \mathrm{CI}=[1.06,4.60], p=$ .002 , whereas it was not significantly different from zero for the individuals experiencing financial equilibrium, $b=-0.01,95 \% \mathrm{CI}=[-0.96,0.94], p=.982$, or abundance, $b=-0.16,95 \% \mathrm{CI}=[-1.01,0.66], p=.700$. The interaction between the Gini coefficient and the orthogonal contrast was not significant, $b=0.16,95 \% \mathrm{CI}=[-0.89,1.19], p=$ .769 .

\section{Supplemental analysis.}

Predictive utility of financial scarcity versus income. As in the WVS data, as a second step, we included the interaction between the Gini coefficient and (standardized) income in our main model. The interaction was not significant, $b=0.18,95 \% \mathrm{CI}=[-0.41,0.76], p=.545$. A postestimation test of coefficients again suggested that the Gini Coefficient $\times$ Scarcity interaction had a higher predictive utility than the Gini Coefficient $\times$ Income interaction, $\chi^{2}(1, N=81,600)=9.82, p=.002$.

Robustness check against measurement error. Following the same approach as Cullati, Courvoisier, and Burton-Jeangros (2014), we sought to combine the SHP variables depression, blues, anxiety: frequency and frequency of energy and optimism (reverse-coded) into a single score for psychological health problems. The two items were well correlated $(r=.45, p<.001)$, and we computed the mean (0, least problematic, to 10 , most problematic; $M=2.39, S D=1.63)$. We then built the same multilevel model as before, using this composite score for psychological health problems as the outcome variable. The interaction between the Gini coefficient and the planned contrast remained significant, $b=2.05,95 \%$ $\mathrm{CI}=[0.73,3.42], p=.003$ (for the simple slopes and the full set of results, see the Supplemental Material, including Table S5).

\section{General Discussion}

The present research offers evidence that income inequality affects the psychological health of only the 


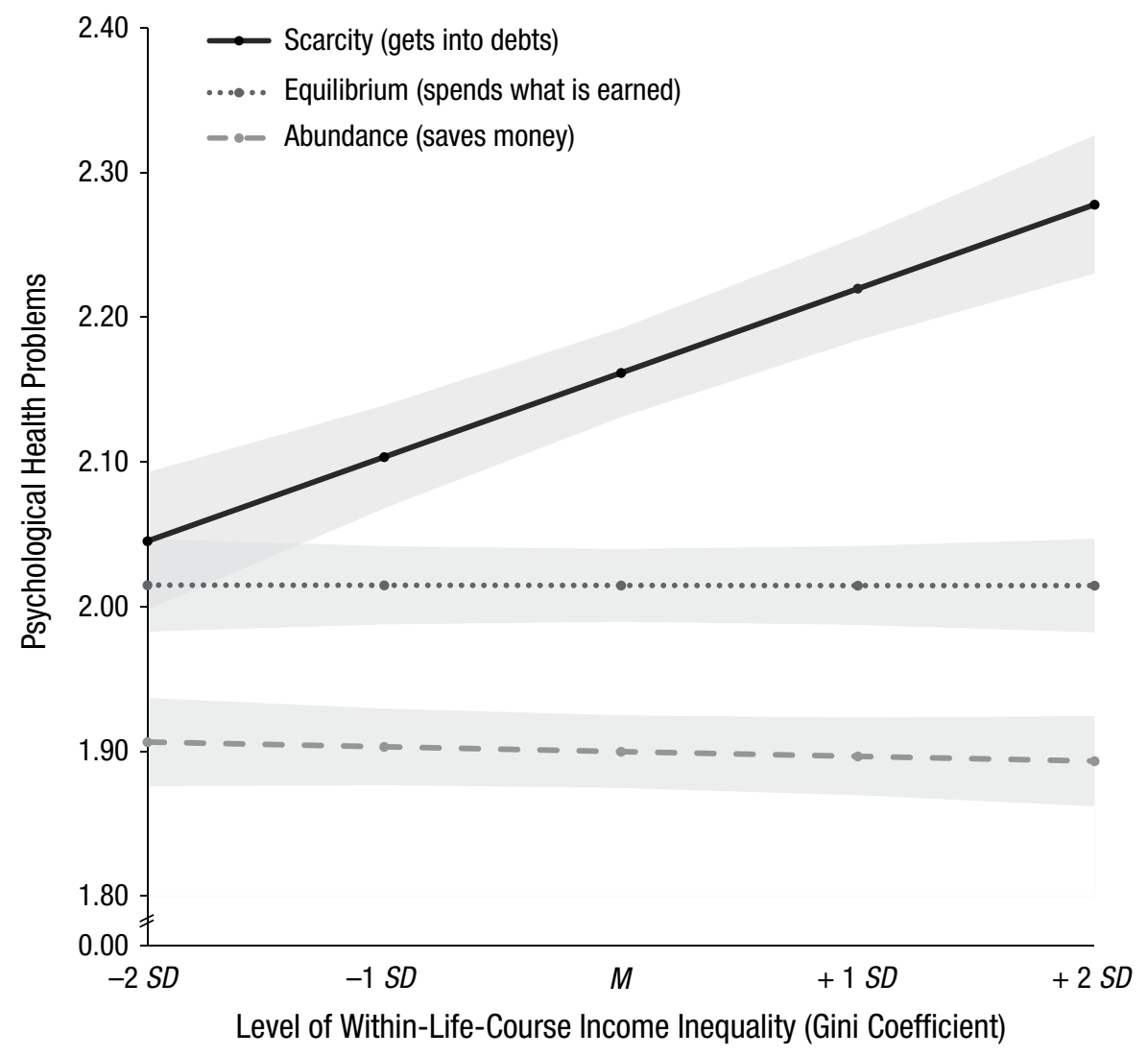

Fig. 2. Swiss Household Panel data: within-life-course effects of income inequality on psychological health problems for individuals in a situation of financial scarcity, equilibrium, or abundance. Shaded areas represent standard deviation from the mean; for the sake of readability, the $y$-axis is scaled from 1.80 to 2.40 (although the possible values of psychological health problems range from 0.00 to 10.00 ).

people facing scarcity. First, using repeated crosssectional international data, we showed that national income inequality predicts stronger feelings of unhappiness among individuals facing financial scarcity $(\approx 25 \%$ of the surveyed world population). Second, using longitudinal Swiss data, we showed that local income inequality predicts more psychological health problems among the individuals facing financial scarcity $(<10 \%$ of the Swiss population). Regarding the mechanism that may account for such a phenomenon, it is at least plausible that income inequality triggers a negative emotional reaction to upward comparison among individuals facing financial scarcity (e.g., hopelessness), making them even more vulnerable to financial stress. However, in both data sets, people experiencing financial equilibrium or abundance were broadly unaffected by income inequality. Importantly, this does not rule out the possibility that some of these people are affected by income inequality (e.g., those who feel guilty for being better off or fearful of losing their economic position).
In both the WVS and SHP data, the interaction between the Gini coefficient and the financial-scarcity measure was found to have better predictive utility than the interaction between the Gini coefficient and income. This finding suggests that financial scarcity may better capture the active ingredient of being economically vulnerable than does income. For instance, one could imagine a low-income individual having such low expenditures that he or she would not necessarily be susceptible to the adverse effects of income inequality; conversely, one could imagine a middle- or even highincome individual having to handle unanticipated expenses and suddenly becoming vulnerable (e.g., following a divorce or a health problem). By extension, this finding also suggests that one could develop a measure of financial-scarcity-based inequality as an alternative to the traditional measures of income-based inequality.

Relatedly, in both the WVS and SHP data, individuals experiencing financial scarcity reported stronger feelings 
of unhappiness and more psychological health problems than individuals experiencing financial equilibrium or abundance. This pattern of findings was even observed at a low level of income inequality, highlighting the fact that the financial-scarcity measure used in the present research may work as a reliable predictor of psychologicalwell-being outcomes. Presumably, the experience of financial scarcity reduces one's ability to cope with financial stressors (such as income inequality), thereby leading to chronic stress (see Haushofer \& Fehr, 2014).

Three limitations should be acknowledged. First, financial scarcity was a single-item measure. Despite the sufficient number of clusters, measurement error is likely to affect coefficient estimates. Future studies using primary data should incorporate a multi-item scale. Second, despite the longitudinal nature of the SHP data, there is a (less parsimonious) possibility of reverse causality: People facing financial scarcity may become increasingly more anxious over time, which may diminish their economic productivity and deepen inequality. Experimentally manipulating income inequality and financial scarcity or-more feasiblyinvestigating their prospective lagged effects on psychological health (e.g., see Zheng, 2012) may be an avenue for further research. Third, our second set of data was collected in Switzerland. Given the similarity between the global (worldwide) findings observed in the WVS data and the specific (Swiss) findings observed in the SHP data, we would not expect a different pattern in another developed country. Still, replications using longitudinal data from different countries are warranted.

In conclusion, this research shows that the effects of income inequality on feelings of unhappiness and psychological health problems are mostly limited to individuals facing financial scarcity. This finding challenges the often-expressed idea that reducing income inequality will result in the betterment of all, not just the poor. Our results suggest that income inequality by itself may not be a problem for psychological health but rather is a catalyst for the detrimental consequences of economic vulnerability. Instead of focusing exclusively on the main effects of income inequality, determining who is susceptible to the damaging psychological consequences of income inequality and who is not may be more relevant.

\section{Action Editor}

Ian H. Gotlib served as action editor for this article.

\section{Author Contributions}

N. Sommet developed the study concept. N. Sommet gathered and analyzed the data and interpreted the results under the supervision of D. Morselli and D. Spini. N. Sommet drafted the manuscript, and D. Morselli and D. Spini provided critical revisions. All the authors approved the final manuscript for submission.

\section{Acknowledgments}

We wish to thank Roger Ammann for his help in gathering the Swiss municipal economic indicators, as well as the CoCo/ Résilience group members for their helpful comments and suggestions.

\section{Declaration of Conflicting Interests}

The author(s) declared that there were no conflicts of interest with respect to the authorship or the publication of this article.

\section{Funding}

This article is based on research conducted at the Swiss National Centre of Competence in Research LIVES-Overcoming vulnerability: Life course perspectives, which is financed by the Swiss National Science Foundation.

\section{Supplemental Material}

Additional supporting information can be found at http:// journals.sagepub.com/doi/suppl/10.1177/0956797618798620

\section{Open Practices}

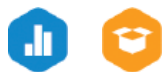

In this research, we used survey-based data (i.e., the World Values Survey and Swiss Household Panel) that are publically available (http://www.worldvaluessurvey.org/ and http:// forscenter.ch/en/our-surveys/swiss-household-panel/, respectively), and we have shared the complete materials (the source, the wording, and a link for each variable), the raw economic data (i.e., the World Bank and Swiss Federal Statistical Office data), our Stata .do files, and the complete instruction to reproduce the findings (https://figshare.com/s/0bfe19464 337b17fb326). The complete Open Practices Disclosure for this article can be found at http://journals.sagepub.com/doi/ suppl/10.1177/0956797618798620. This article has received the badges for Open Data and Open Materials. More information about the Open Practices badges can be found at http:// www.psychologicalscience.org/publications/badges.

\section{Notes}

1. For this and the subsequent data set, descriptive statistics are provided for the nonimputed variables.

2. In the WVS data, the effect of income inequality was stronger for families who "spent some savings and borrowed money" than for those who "spent savings and borrowed money," $b=$ $0.95,95 \% \mathrm{CI}=[0.30,1.61], p=.004$, whereas in the SHP data, the effect did not differ between the two subgroups, $b=2.06,95 \%$ $\mathrm{CI}=[-2.73,6.84], p=.395$. This finding suggests that the degree of financial scarcity may matter in some instances. However, we chose not to distinguish between low- and high-scarcity subgroups (a) to avoid having a small number of participants per subgroup (e.g., only $1.30 \%$ of the SHP households "get into debt") and (b) because the distinction between low- and highabundance subgroups could not be applied symmetrically.

3. For this and the subsequent data set, this model used nonimputed income. Thus, the sample size was slightly smaller. 
4. The employment-to-population ratio was available only for 1995, 2001, 2005, 2008, and 2011 to 2014. The value from the closest year was used when the estimate was missing.

\section{References}

Ahern, J., \& Galea, S. (2006). Social context and depression after a disaster: The role of income inequality. Journal of Epidemiology \& Community Health, 60, 766-770.

Blascovich, J. (2013). Challenge and threat. In A. J. Elliot (Ed.), Handbook of approach and avoidance motivation (pp. 431-446). New York, NY: Psychology Press.

Burns, J. K., Tomita, A., \& Lund, C. (2017). Income inequality widens the existing income-related disparity in depression risk in post-apartheid South Africa: Evidence from a nationally representative panel study. Health \& Place, $45,10-16$.

Buttrick, N. R., \& Oishi, S. (2017). The psychological consequences of income inequality. Social \& Personality Psychology Compass, 11(3), Article e12304. doi:10.1111/spc3.12304

Cheung, F., \& Lucas, R. E. (2016). Income inequality is associated with stronger social comparison effects: The effect of relative income on life satisfaction. Journal of Personality and Social Psychology, 110, 332-341.

Cullati, S., Courvoisier, D. S., \& Burton-Jeangros, C. (2014). Mental health trajectories and their embeddedness in work and family circumstances: A latent state-trait approach to life-course trajectories. Sociology of Health E Illness, 36, 1077-1094.

Diener, E., Diener, M., \& Diener, C. (1995). Factors predicting the subjective well-being of nations. Journal of Personality and Social Psychology, 69, 851-964.

Dunn, E. C., Richmond, T. K., Milliren, C. E., \& Subramanian, S. V. (2015). Using cross-classified multilevel models to disentangle school and neighborhood effects: An example focusing on smoking behaviors among adolescents in the United States. Health E Place, 31, 224-232.

Enders, C. K., \& Tofighi, D. (2007). Centering predictor variables in cross-sectional multilevel models: A new look at an old issue. Psychological Methods, 12, 121-138.

Goldthorpe, J. H. (2010). Analysing social inequality: A critique of two recent contributions from economics and epidemiology. European Sociological Review, 26, 731-744.

Haushofer, J., \& Fehr, E. (2014). On the psychology of poverty. Science, 344, 862-867.

Hiilamo, H., \& Kangas, O. (2014). Cherry picking: How sensitive is the relationship between inequality and social problems to country samples? International Journal of Sociology and Social Policy, 34, 771-792.

Johnston, C. D., \& Newman, B. J. (2016). Economic inequality and U.S. public policy mood across space and time. American Politics Research, 44, 164-191.

Kelley, J., \& Evans, M. D. R. (2017). Societal inequality and individual subjective well-being: Results from 68 societies and over 200,000 individuals, 1981-2008. Social Science Research, 62, 1-23.

Keltner, D., Gruenfeld, D. H., \& Anderson, C. (2003). Power, approach, and inhibition. Psychological Review, 110, 265-284.
Layte, R. (2011). The association between income inequality and mental health: Testing status anxiety, social capital, and neo-materialist explanations. European Sociological Review, 28, 498-511.

Layte, R., \& Whelan, C. T. (2014). Who feels inferior? A test of the status anxiety hypothesis of social inequalities in health. European Sociological Review, 30, 525-535.

Lin, Y., Zhang, Q., Chen, W., \& Ling, L. (2017). The social income inequality, social integration and health status of internal migrants in China. International Journal for Equity in Health, 16, Article 139. doi:10.1186/s12939-017-0640-9

Mani, A., Mullainathan, S., Shafir, E., \& Zhao, J. (2013). Poverty impedes cognitive function. Science, 341, 976-980.

Mullainathan, S., \& Shafir, E. (2014). Scarcity: The new science of having less and how it defines our lives. New York, NY: Picador.

Ngamaba, K. H., Panagioti, M., \& Armitage, C. J. (2017). Income inequality and subjective well-being: A systematic review and meta-analysis. Quality of Life Research, 27, 577-596.

Oishi, S., Kesebir, S., \& Diener, E. (2011). Income inequality and happiness. Psychological Science, 22, 1095-1100.

Oshio, T., \& Urakawa, K. (2014). The association between perceived income inequality and subjective well-being: Evidence from a social survey in Japan. Social Indicators Research, 116, 755-770.

Pickett, K. E., \& Wilkinson, R. G. (2017). Immorality of inaction on inequality. British Medical Journal, 356, Article j556. doi:10.1136/bmj.j556

Piketty, T., \& Saez, E. (2014). Inequality in the long run. Science, 344, 838-843.

Präg, P., Mills, M., \& Wittek, R. (2013). Income and income inequality as social determinants of health: Do social comparisons play a role? European Sociological Review, 30, 218-229.

Ribeiro, W. S., Bauer, A., Andrade, M. C. R., York-Smith, M., Pan, P. M., Pingani, L., . . . Evans-Lacko, S. (2017). Income inequality and mental illness-related morbidity and resilience: A systematic review and meta-analysis. The Lancet Psychiatry, 4, 554-562.

Rosenthal, R., \& Rosnow, R. L. (1985). Contrast analysis: Focused comparisons in the analysis of variance. Cambridge, England: Cambridge University Press.

Roth, B., Hahn, E., \& Spinath, F. M. (2017). Income inequality, life satisfaction, and economic worries. Social Psychological \& Personality Science, 8, 133-141.

Rözer, J., \& Kraaykamp, G. (2013). Income inequality and subjective well-being: A cross-national study on the conditional effects of individual and national characteristics. Social Indicators Research, 113, 1009-1023.

Schneider, S. M. (2016). Income inequality and subjective wellbeing: Trends, challenges, and research directions. Journal of Happiness Studies, 17, 1719-1739.

Singh-Manoux, A., Adler, N. E., \& Marmot, M. G. (2003). Subjective social status: Its determinants and its association with measures of ill-health in the Whitehall II study. Social Science E Medicine, 56, 1321-1333.

Snowdon, C. (2010). The spirit level delusion: Fact-checking the left's new theory of everything. Ripon, England: Little Dice. 
Sturm, R., \& Gresenz, C. R. (2002). Relations of income inequality and family income to chronic medical conditions and mental health disorders: National survey. British Medical Journal, 324, 20-23.

Subramanian, S. V., \& Kawachi, I. (2006). Whose health is affected by income inequality? A multilevel interaction analysis of contemporaneous and lagged effects of state income inequality on individual self-rated health in the United States. Health Place, 12, 141-156.

Van Deurzen, I., Van Ingen, E., \& Van Oorschot, W. J. (2015). Income inequality and depression: The role of social comparisons and coping resources. European Sociological Review, 31, 477-489.
Wilkinson, R. G., \& Pickett, K. E. (2006). Income inequality and population health: A review and explanation of the evidence. Social Science \& Medicine, 62, 1768-1784.

Wilkinson, R., \& Pickett, K. (2010). The spirit level: Why greater equality makes societies stronger. New York, NY: Bloomsbury Press.

Zagorski, K., Evans, M. D., Kelley, J., \& Piotrowska, K. (2014). Does national income inequality affect individuals' quality of life in Europe? Inequality, happiness, finances, and health. Social Indicators Research, 117, 1089-1110.

Zheng, H. (2012). Do people die from income inequality of a decade ago? Social Science \& Medicine, 75, 36-45. 